\title{
A comparative Study of Motivation and Learning Strategies Between High School and University Students
}

\section{Dr. Quamrul H. Mazumder, University of Michigan, Flint}

Dr. Quamrul Mazumder is currently an associate professor of mechanical engineering at University of Michigan-Flint. His areas of research include computational fluid dynamics, multiphase flow, quality in higher education, metacognition, motivation, and engagement of students. He is a Fulbright scholar travelled around the world to promote quality and globalization of higher education.

\section{Dr. Ulan Dakeev, University of Michigan, Flint}

Dr. Ulan Dakeev is currently a faculty of mechanical engineering at the University of Michigan-Flint. His areas of research include renewable energy (wind energy), quality in higher education, motivation, and engagement of students. 


\title{
A Comparative Study of Motivation and Learning Strategies between High School and University Students
}

\begin{abstract}
To compare the level of motivation and strategies used by high school and university students, a study was conducted between two groups of students. One group was high school students who were dual enrolled in university courses and the other group was first year university students. Both groups were enrolled in similar courses with instructors using similar teaching methods and materials. The study used a Motivated Strategy Learning Questionnaire (MSLQ) that consisted of 18 categories, of which 6 related to motivation and 9 related to learning strategies. The participants included fifty two high school students and forty five university students. An independent sample t-test and variance analysis were performed to compare the responses of these two groups of students. The analysis results showed college student with higher levels of motivation and better learning strategies that high school students. Additionally, gender comparison showed Female students are more motivated with better learning strategies than male students.
\end{abstract}

\section{Introduction:}

Previous investigators ${ }^{1,2}$ reported that academic motivation is a powerful factor for students in terms of completing their academic work and making them more interested toward learning. High school and university students, based on their ${ }^{3}$ theory of learning styles, map the differences in how they learn. Furthermore, there is a relationship between high academic success and self-regulated learning strategies ${ }^{4}$ and it is possible that high school students may be more self-regulated with respect to their learning strategies ${ }^{5}$. Several studies have been conducted on learning strategies and motivation using specific populations like high school and university students. Studies on motivational and learning strategies amongst diverse populations can help to develop an improved perception of how different campus communities, societies and experiences shape students' learning and also aid in the development of effective curriculum. This will enable students to receive better education and take full advantage of learning outcomes at various institutions. Hence, the MSLQ (Motivational Strategy for Learning Questionnaire), a self-report instrument to measure motivational orientation and self-regulated 
learning strategies ${ }^{6}$, is used in the study reported in this paper. The motivation and learning strategy scales are listed below. The MSLQ reliability coefficients, alphas were between 0.52 and 0.93 for different scales validating the instruments higher level of reliability.

Table 1: Motivation and Learning Strategy Scales

\section{Hypothesis}

\begin{tabular}{|c|c|}
\hline Categories & MSLQ Scales \\
\hline \multirow{5}{*}{ 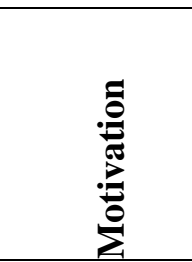 } & Rehearsal \\
\hline & Elaboration \\
\hline & Organization \\
\hline & Critical Thinking \\
\hline & Metacognitive Self-regulation \\
\hline \multirow{6}{*}{ 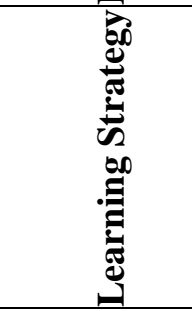 } & Intrinsic Goal Orientation \\
\hline & Extrinsic Goal Orientation \\
\hline & Task Value \\
\hline & Control of Learning \\
\hline & Self-efficacy \\
\hline & Test Anxiety \\
\hline \multirow{4}{*}{ 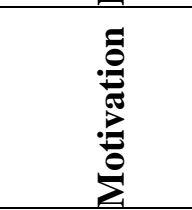 } & Time/Study Management \\
\hline & Effort Regulation \\
\hline & Peer Learning \\
\hline & Help Seeking \\
\hline \multirow{3}{*}{$\stackrel{\dot{\Xi}}{\tilde{0}}$} & Theory of Intelligence \\
\hline & Achievement Goal Questionnaire \\
\hline & Percentage of Instrumentality \\
\hline
\end{tabular}

To evaluate motivation and learning strategies of high school students and university students, two hypotheses were examined in the current work.

1. There is no significant difference between high school and college/university level students

2. There is no significant difference between males and females in both college/university and high school level students. 


\section{Literature Review}

The MSLQ is more narrowly focused and oriented similarly; it encompasses students' motivation and their learning strategies, thereby providing different information. It is based on important theoretical insights into the nature of learning and the determinants of academic performance $^{7}$ which have been used by several studies. Self-regulated learning is an integrated learning process, which consists of behavior growth that affects students' learning. Moreover, the learning process is planned and adjusted according to the student's objective, so that changes will be made in the learning situation ${ }^{8}$. It is dimensionally constructed and includes at least three aspects which include but are not limited to cognition, individual motivation and goal directed behavior ${ }^{9}$.

Academic performance has been widely reported to correlate significantly and positively with the choice and application of self-regulated learning strategies ${ }^{10}$. However, learning strategies involve students who engage in self-regulated learning and can be defined as learners who effectively control their own learning experiences in many different ways including organizing information to be learned, holding positive beliefs about their own capabilities, and valuing learning. Motivational strategies are closely related to the grades of university students. However, the most robust factors for motivation and learning strategies could be self-efficacy and effort regulation.

\section{Research methodology:}

\section{Questionnaire:}

Data was collected using the Motivated Strategies Learning Questionnaire, developed originally by Pintrich, Smith, Gracia \& Mckeavhie ${ }^{11}$. The questionnaire is an 81-item, selfreported, Likert-scaled instrument which students use to rate statements about their motivational orientation and use the different learning strategies for a specific course from " 1 " (not at all true for me) to " 7 "' (very true for me) ${ }^{12}$.

\section{Participants:}

The questionnaire was distributed to High school (52) and College Level (45) students as illustrated in Figure 1 below. A total number of 97 students participated in the current study. 


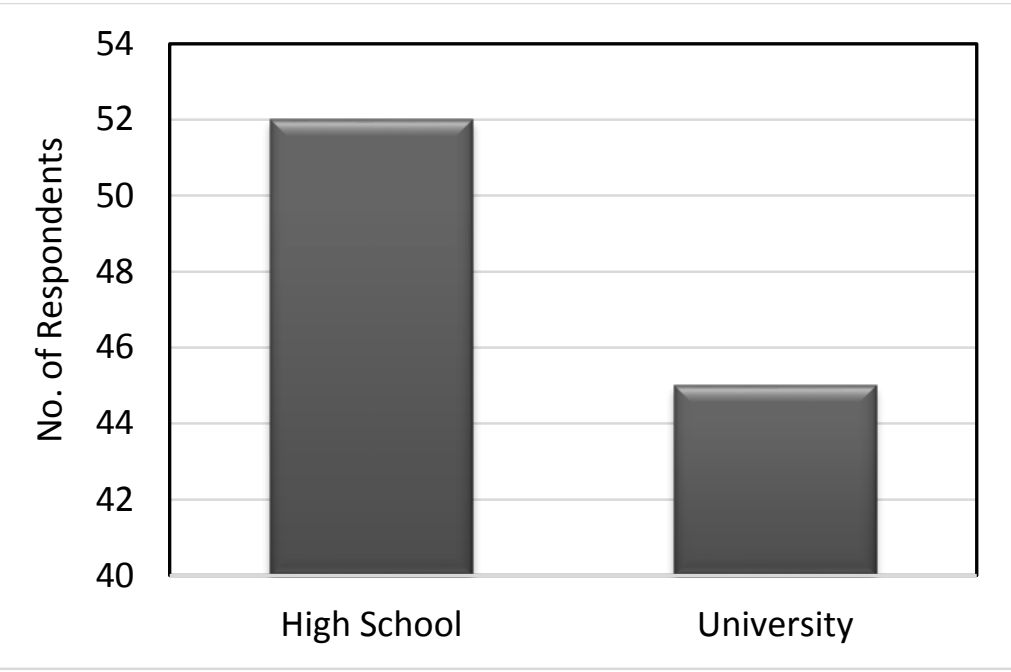

Figure 1: Number of Respondents by Institution

Forty seven male and five female students from university and thirty one male and thirteen female high school students participated in the study. The survey questionnaire was sent to 52 high school students and 77 university students in fall and winter semesters. The overall response rate was 96 out of 129 (74\%) as the responses were voluntary with no incentive to the students. The percentage of male and female participants were $80 \%$ and $19 \%$ as shown in figures 1 and 2. This closely represents the distribution of male and female students in undergraduate engineering classes. One of the hypotheses of this study was to investigate differences between male and female students; therefore one undefined student was omitted from the statistical analysis as the student did not want to disclose the information.

\begin{tabular}{|l|l|l|l|l|}
\hline \multicolumn{2}{|l|}{} & Males & Females & Undefined \\
\hline Institution & Mniversity & 47 & 5 & 0 \\
\hline High School & 31 & 13 & 1 \\
\hline Total & 78 & 18 & 1 \\
\hline Percent & $80.41 \%$ & $18.56 \%$ & $1.03 \%$ \\
\hline
\end{tabular}

Figure 2: Gender Distribution of Respondents 


\section{Data Analysis/Procedure:}

Statistical analyses were performed using independent sample t-test and F-test to determine the mean values of 18 categories among students. SPPS22 statistical analysis software was used for the analysis. The purposes of this test were to determine if there is any significant difference between:

- High school and college/university students

- Male \& Female students

\section{Results:}

Statistical analyses were performed using independent sample t-test, variance $(\mathrm{F})$, and descriptive statistics to compare high school and college/university students (hypothesis one) as well as male and female students (hypothesis two). Tables 2 and 3 summarize the analyses results related to hypothesis one and tables 3 and 4 summarize the results related to hypothesis two.

Table 2: Descriptive Statistics of High School and College/University Students

\begin{tabular}{|l|l|l|l|l|l|}
\hline \multicolumn{2}{|l|}{} & $\mathrm{N}$ & Mean & $\begin{array}{l}\text { Std. } \\
\text { Deviation }\end{array}$ & $\begin{array}{l}\text { Std. } \\
\text { Error } \\
\text { Mean }\end{array}$ \\
\hline \multirow{2}{*}{$\begin{array}{l}\text { Task Value } \\
\text { (Motivation) }\end{array}$} & $\begin{array}{l}\text { High } \\
\text { School }\end{array}$ & 52 & 5.01 & 1.89 & 0.26 \\
\cline { 2 - 6 } College & 45 & 5.53 & 1.43 & 0.21 \\
\hline $\begin{array}{l}\text { Peer Learning } \\
\text { (Learning } \\
\text { Strategy) }\end{array}$ & $\begin{array}{l}\text { High } \\
\text { School }\end{array}$ & 52 & 4.12 & 1.95 & 0.27 \\
\cline { 2 - 6 } & College & 45 & 4.52 & 1.54 & 0.23 \\
\hline $\begin{array}{l}\text { Percent } \\
\text { Instrumentality } \\
\text { (Other) }\end{array}$ & $\begin{array}{l}\text { High } \\
\text { School }\end{array}$ & 52 & 4.31 & 1.75 & 0.24 \\
\cline { 2 - 6 } & College & 45 & 4.67 & 1.19 & 0.18 \\
\hline
\end{tabular}

Statistical analysis results are presented on the categories that showed significant differences between high school and college/university students. Three different categories are presented, one from motivation (Task Value), one from learning strategy (Peer Learning) and one from others (Percent Instrumentality). Task Value measures students' perception of the course materials in terms of interest, importance and utility in the future. Peer learning refers to 
the extent of dialogue students have with peers to clarify course materials and reach insights that may not have been attained on their own. Percent Instrumentality refers to students' perception of the importance and usefulness of information learned in math classes in future classes, education, academic and occupational success. The mean values in all three categories were higher for college/university students (4.52 to 5.53) when compared with high school students (4.12 to 5.01) showing that the college students have better study skills, more effective peer learning and higher scores in percent instrumentality. This may be attributed to students' level of maturity and exposure to different learning environments between high school and colleges.

Table 3: Sample t-test and variance (F) for High School and College/University Students

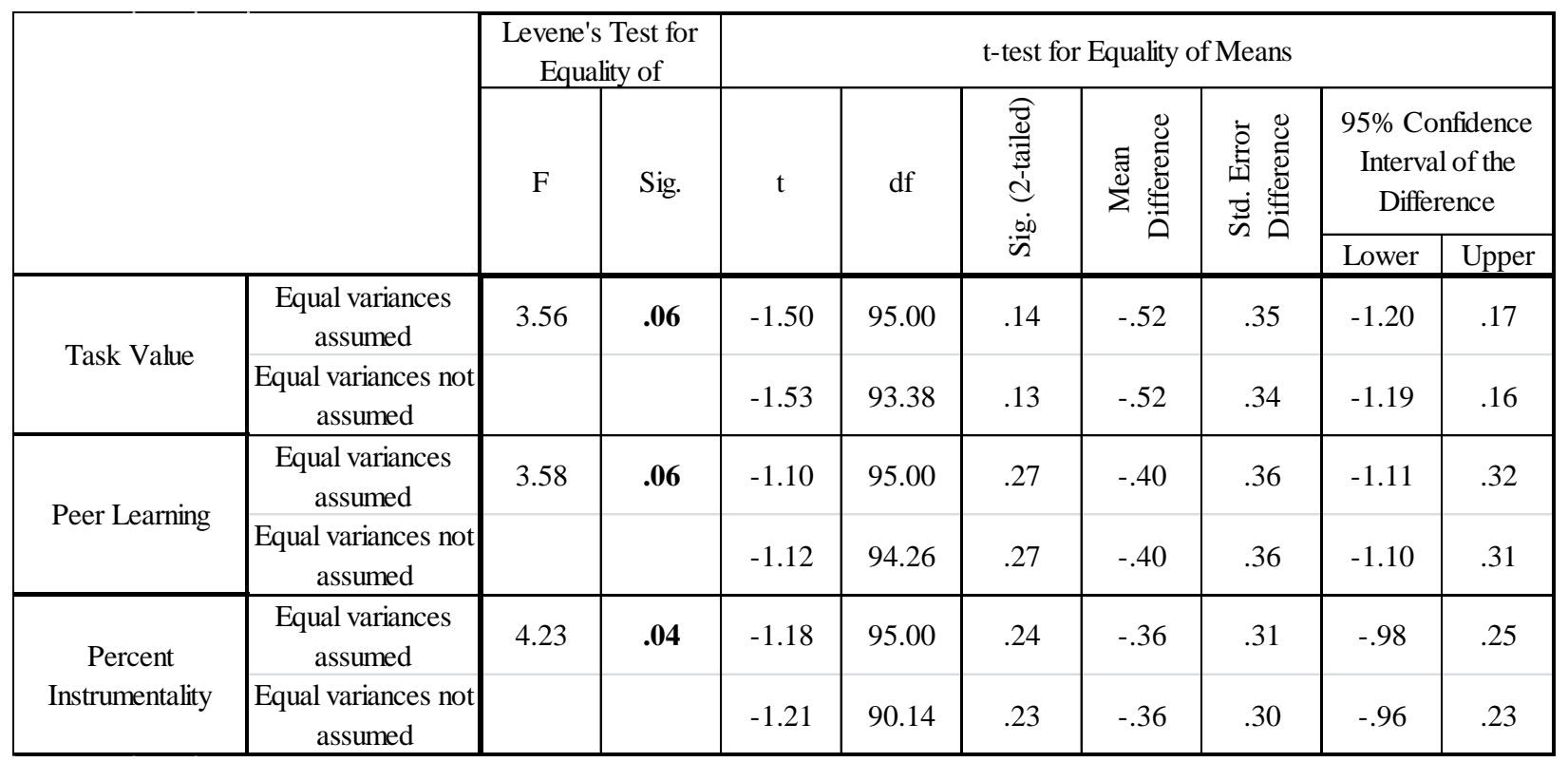

The independent sample t-test and F-test results for high school and college/university students are presented in Table 3. Analyses were performed assuming both equal and not equal variances to evaluate any significant differences. No significant difference was observed in the results of t-test for equality of means. However, significant differences were observed in Levene's F-test for equality in the category of percent instrumentality $(p=0.04 \leq 0.05)$. This refers to the fact that more college students believe that the information learned in math classes is important and useful in future classes, education, academic and occupational success compared to high school students. 
Table 4: Descriptive Statistics of Male and Female Students

\begin{tabular}{|c|c|c|c|c|c|}
\hline Category & Gender & $\mathrm{N}$ & Mean & $\begin{array}{l}\text { Std. } \\
\text { Deviation }\end{array}$ & $\begin{array}{l}\text { Std. } \\
\text { Error } \\
\text { Mean }\end{array}$ \\
\hline \multirow{2}{*}{\begin{tabular}{|l|} 
Extrinsic \\
(Motivation)
\end{tabular}} & Female & 18 & 5.97 & 0.80 & 0.19 \\
\hline & Male & 79 & 5.17 & 1.87 & 0.21 \\
\hline \multirow{2}{*}{$\begin{array}{l}\text { Task Value } \\
\text { (Motivation) }\end{array}$} & Female & 18 & 5.81 & 0.78 & 0.18 \\
\hline & Male & 79 & 5.12 & 1.83 & 0.21 \\
\hline \multirow{2}{*}{$\begin{array}{l}\text { Time Study } \\
\text { Mgt. } \\
\text { (Learning } \\
\text { Strategy) }\end{array}$} & Female & 18 & 4.97 & 0.49 & 0.12 \\
\hline & Male & 79 & 4.63 & 1.52 & 0.17 \\
\hline \multirow{2}{*}{$\begin{array}{l}\text { Help Seeking } \\
\text { (Learning } \\
\text { Strategy) }\end{array}$} & Female & 18 & 3.66 & 0.80 & 0.19 \\
\hline & Male & 79 & 3.68 & 1.61 & 0.18 \\
\hline \multirow{2}{*}{\begin{tabular}{|l|} 
Percentage of \\
Instrumentality \\
(Others) \\
\end{tabular}} & Female & 18 & 4.88 & 0.50 & 0.12 \\
\hline & Male & 79 & 4.38 & 1.66 & 0.19 \\
\hline
\end{tabular}

Statistical analysis results are presented on the categories that showed significant differences between male and female students in five different categories. Two of these categories are in motivation (extrinsic goal orientation and task value), two are in learning strategy (time/study environment management and help seeking), and one is from others (percentage of instrumentality). Extrinsic goal orientation concerns the degree to which a student perceives himself or herself to be participating in a task for reasons such as grades, rewards, performance, evaluation by others and competitions. Time and study environment management involves scheduling, planning and managing one's study time. Study environment refers to the setting where the student studies or does the class work. Help seeking includes seeking help from both peers, tutors, instructors and others to comprehend course materials and academic success. The mean values in four of the five categories were higher for female students ( 4.88 to 5.97) compared to male students (4.12 to 5.01). Male students scored 3.68 compared to 3.66 of female students in help seeking showing that male students are more active in seeking help from peers and instructors. 
Table 5: Sample t-test and variance (F) for Male and Female Students

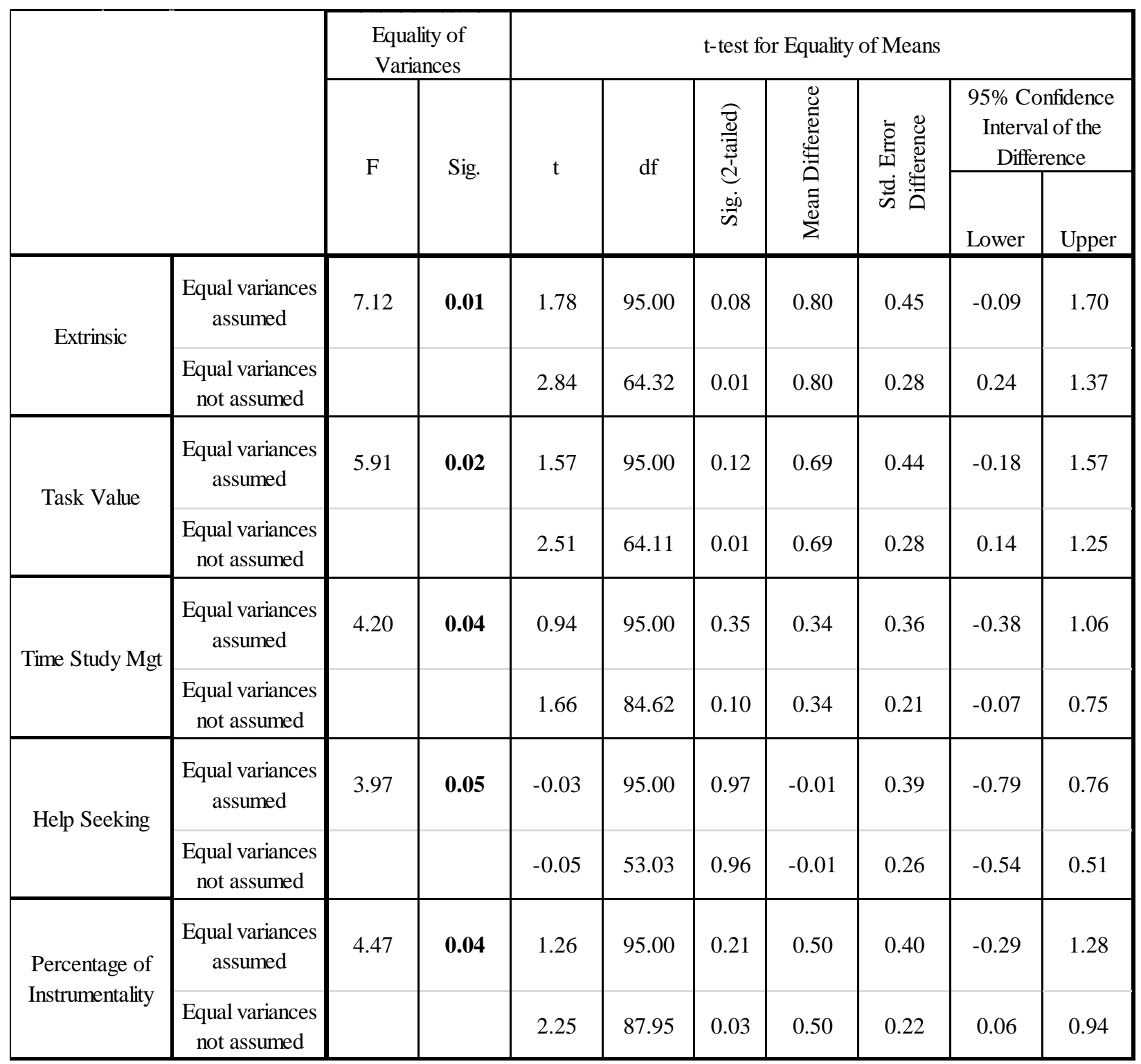

The independent sample t-test and F-test results for male and female students are presented in Table 5. Analyses were performed assuming both equal and not equal variances to evaluate any significant differences. Significant differences were observed in the results of ttest for extrinsic $(\mathrm{p}=0.01 \leq 0.05)$, task value $(\mathrm{p}=0.01 \leq 0.05)$ and percentage of instrumentality $(p=0.03 \leq 0.05)$. Significant differences were observed in Levene's F-test in all five categories listed in Table $5(\mathrm{p}=0.01,0.02,0.04,0.05,0.04 \leq 0.05)$. 


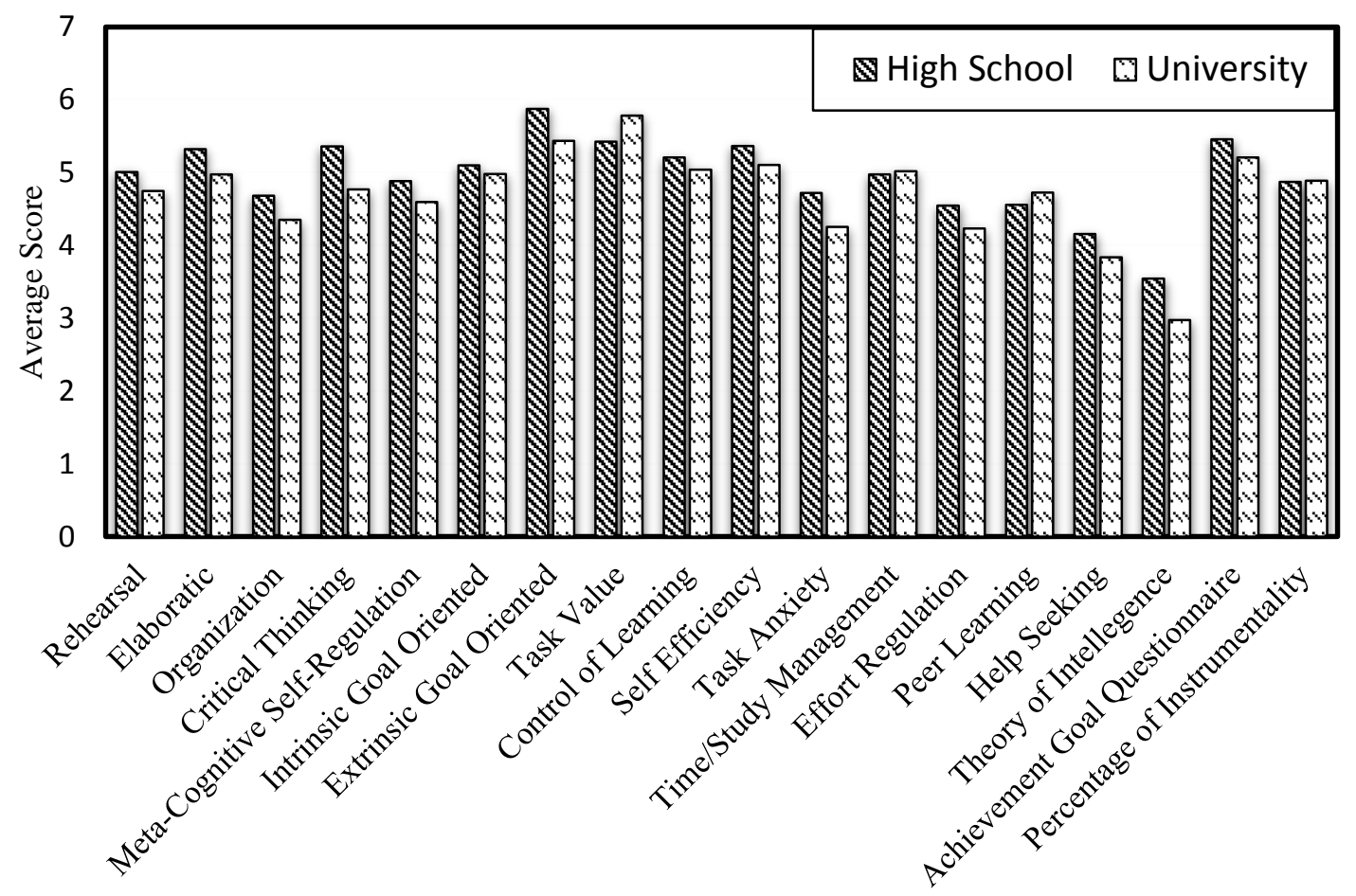

Figure 3: Comparison of Mean Scores of High School \& University Students

The mean MSLQ scores of high school students and college/university students for all eighteen categories are presented in Figure 3. Higher scores were observed in extrinsic goal orientation, task value and achievement goal questionnaires. The lowest scores were in theory of intelligence and help seeking categories.

\section{Summary and Conclusion:}

The study revealed an important distinction between dual enrolled high school students and college students as well as male and female students in first year engineering classes. The study used the MSLQ questionnaire, a widely used instrument with high reliabilities. The study measured to what extent students will use the material learned in a specific class in other classes. It also measured whether the grade received in the class was relevant and important to their learning process. The results indicated college students believe the material to be more relevant and useful to other classes compared to high school students. College students showed higher level of recognition of grades as related to their learning and academic success. 
High school students dual enrolled in college courses are among the high achieving students in their class and supposedly have better academic preparation than first year college students. However, the current study results showed higher levels of motivation and better learning strategies among college/university students.

Significant differences were observed between male and female students in both high schools and universities in extrinsic goal orientation, task value, time/study management, help seeking and percentage of instrumentality $(\mathrm{p}<0.05)$. Female students showed higher extrinsic goal orientation, higher task value, better time/study management skills and higher percentage of instrumentality compared to male students, whereas, male students were more active in help seeking to improve their learning process.

Overall, college students are more motivated and better learners than high school students and female students showed higher level of motivation towards academic success than male students. The study was based on a limited number of students and will be extended to a larger population to better understand the characteristics of high school and college students. Although these results may not lead to conclusions about the motivation and learning strategies of these two groups of students, they shed some light on an extremely important topic about how to motivate students towards success in engineering.

\section{Acknowledgement:}

The authors would like to thank University of Michigan Flint dual enrollment extended partnership (DEEP) program for their support in collecting data from high school students, institutional review board of office of research, mechanical engineering program and undergraduate research opportunity programs (UROP).

\section{References}

[1] Lavasani, M. G., Mirhosseini, F. S., Hejazi, E., \& Davoodi, M. (2011). The effect of self-regulation learning strategies training on the academic motivation and self-efficacy. Procedia - Social and Behavioral Sciences; 29 (2011), 627 - 632. 
[2] Artino, R. A., \& Stephens, M. J. (2008). Promoting Academic Motivation and Self-Regulation: Practical Guidelines for Online Instructors. Society for Information Technology \& Teacher Education International Conference. ISBN 978-1-880094-64-8

[3] Zajacova, B. (2013). Learning styles in physics education: introduction of our research tools and design. Procedia-Social and Behavioral Sciences; 106 (2013), 1786-1795.

[4] Salamonson, Y., Everett, B., Koch, J., Wilson, I., Davidson, M. P. (2009). Learning strategies of first year nursing and medical students: A comparative study. International Journal of Nursing Studies; 46 (2009), $1541-1547$.

[5] Mazumder, Q. H., Karim, R. M. (2012). Comparative Analysis of Learning Styles of Students of USA and Bangladesh, Paper no: AC2012-5075, 119th ASEE Annual Conference, June 10-13, 2012, San Antonio, TX, USA

[6] Sadi, O. \& Uyar, M. (2013). The relationship between cognitive self-regulated learning strategies and biology achievement: A path model. Procedia-Social and Behavioral Sciences; 93 (2013), 847-852.

[7] Crede, M., \& Philips, A. L. (2011). A meta-analytic review of the motivated strategies for learning questionnaire. Learning and Individual Differences; 21 (2011), 337-346.

[8] Puteha, M., \&, Ibrahimb, M. (2010). The usage of self-regulated learning strategies among form four students in the mathematical problem-solving context: A Case Study. Procedia Social and Behavioral Sciences; 8 (2010), 446-452.

[9] Jacobson, R. R., \& Harris, M. S. (2008). Does the type of campus influence self-regulated learning a measured by the motivated strategies for learning questionnaire (MSLQ). Institute of Educational Sciences; 128 (2008), 412-431

[10] Arsal, Z. (2010). The effects of diaries on self-regulation strategies of persevere science teachers. International Journal of Environmental \& Science Education, 5(1), 85-103.

[11] Pintrich, P. R., Smith, D. A., Garcia, T., \& McKeachie, W. J (1993). Reliability and predictive validity of the motivated strategies for learning questionnaire. Educational and Psychology Measurement; 53(1993), 801813.

[12] Mazumder, Q. H. and Ahmed, K. (2014). A Comparative Study of Motivation and Learning Strategies Between Public and Private University Students of Bangladesh. Proceedings of the 2014 ASEE North Central Section Conference, April 4-5, 2014, Oakland University, USA 